DIGITALCOMMONS @WAYNESTATE-
Michigan Journal of Counseling:

Research, Theory and Practice

Volume 38 | Issue 2

Article 2

9-1-2011

\title{
Individual and Family Correlates of Adolescents' Sexual Behavior: Multiethnic Findings
}

Claudia Anagurthi

Wayne State University

Ashley Cahill Johnson

Wayne State University

Cheryl L. Somers

Wayne State University, c.somers@wayne.edu

Follow this and additional works at: https://digitalcommons.wayne.edu/mijoc

\section{Recommended Citation}

Anagurthi, C., Johnson, A. C., \& Somers, C. L. (2011). Individual and Family Correlates of Adolescents' Sexual Behavior: Multiethnic Findings, Michigan Journal of Counseling, 38(2), 4-16. doi:10.22237/mijoc/1314835260

This Article is brought to you for free and open access by the Open Access Journals at DigitalCommons@WayneState. It has been accepted for inclusion in Michigan Journal of Counseling: Research, Theory and Practice by an authorized editor of DigitalCommons@WayneState. 


\title{
Individual and Family Correlates of Adolescents' \\ Sexual Behavior: Multiethnic Findings
}

\author{
Claudia Anagurthi \\ Wayne State University \\ Ashley Cahill Johnson \\ Wayne State University \\ Cheryl L. Somers \\ Wayne State University
}

\begin{abstract}
The purpose of this study was to examine correlates of adolescent sexual activity, including age of first date, family composition, clarity of long term goals, and maternal and paternal views about premarital sex. There were 672 males and females, three races/ethnicities, both urban and suburban settings, and socioeconomic diversity. Sexual behavior was most related to parental views about premarital sex, adolescents' own values toward premarital sex, clarity of adolescents' long term goals, and the age when adolescents first learned about sexual intercourse. Important implications for sex education are discussed. Potential intervention variations by gender and race/ethnicity should be considered.
\end{abstract}

\section{Correlates of Adolescents' Sexual Behavior: Multiethnic Findings}

Adolescence is a time of exploration of one's own limits. Currently many teenagers discover their own boundaries through risky sexual behaviors. The price for early onset of sexual activity is high; each year over one million teenagers become pregnant and over four million receive the diagnosis of a sexually transmitted disease (STD) (Centers for Disease Control and Prevention, 2006). Additionally, those adolescents that have been victims of sexual abuse are at greater risk of these problems and others, including anxiety and depression (for review, see Saewyc, Pettingell, \& Magee, 2003). HIV diagnosis due to sexual contact is reported as early as age 13 among teenagers in the USA, with the highest prevalence rates among ethnic minorities such as Hispanics and African Americans (Centers for Disease Control and Prevention, 2009). Only $50 \%$ of teen mothers receive their high school diploma by age 22 (Perper, Peterson, \& Manlove, 2010), making pregnancy a significant contributor to high school dropout. The purpose of this study was to examine the contri-

Cheryl L. Somers is an Associate Professor at Wayne State University in the Department of Educational Psychology. She can be contacted at c.somers@wayne.edu. Claudia Anagurthi and Ashley Cahill Johnson are graduate students at Wayne State University. 
butions of potential individual and family correlates to risky sexual behaviors with a multiethnic sample, while considering the role of both parents separately. Specifically, the researchers looked at the relations between sexual attitudes, sexual behaviors, dating patterns, family composition, clarity of long-term goals, parental views, religious beliefs, and timing of education on sexual intercourse. For the current study, the frequency of sexual intercourse and age of first sexual intercourse were selected as the sexual behaviors of interest.

\section{Impact of Parental Communication on Adolescents' Sexual Health Values by Race and Gender}

Most adolescents report that their main sources of sex education are their parents (Lefkowitz, Sigman, \& Au, 2000; Ream \& Savin-Williams, 2005). Amount and quality of family discussions are positively correlated with teenagers' conservative attitudes toward sex (Fiese et al., 2002), although other studies stress the interactional nature of the relations (Coley, Drzal, \& Schindler, 2009). For example, adolescents were shown to communicate about sexuality more when they had positive relationships, as well as a higher frequency of shared activities, with their parents (Muller, Frisco, \& Pearson, 2006). Wyckoff et al. (2008) showed that teenagers with parents who communicated openly about sex were more likely to have fewer sex partners, use contraception, and postpone their sexual debut. Others have found very small relations between parent-adolescent sexual communication and adolescent sexual behavior (Somers \& Vollmar, 2006).

Variations in communication style and the resulting values adolescents may hold about their sexual health behaviors have been found by race and gender, although the research is sparse in this specific domain and often examines mother-daughter communication only. For example, Dittus, Jaccard, and Gordon (1999) found that African-American teenagers held values similar to their mothers' views. Additionally, Somers and Fahlman (2001) found that Caucasians communicated in the least direct manner compared to other ethnic groups, while Hispanic-American parents are more direct in communicating their values to their sons and daughters (Somers \& Fahlman, 2001). Wyckoff et al. (2008) indicated that both females and males communicate about sex with their mothers more than their fathers even though boys do so more with their fathers than do girls. At the same time, teens who communicated more with mothers held the most conservative values (Dilorio, Kelley, \& HockenberryEaton, 1999). Another study revealed that mothers' communications are more associated with daughters' than sons' outcomes (Ballard \& Morris, 1998); however, other studies have found fathers to have a stronger role in teenagers' sexual activity than previously thought (Ohalete, 2007; Moore \& Chase-Lansdale, 2001).

In terms of adolescent willingness to engage in sexual health communication, it has been reported that female adolescents communicate more directly with their mothers than with their fathers (Somers \& Gleason, 2001). Also, the mothers' values were significantly more related to teenager's attitudes toward sexuality (Regnerus, 2005). Most notably, adolescents had a lower rate of risky sexual behaviors (this includes all sexual activity that could pose a risk to the 
teenager or their partner to become pregnant and/or transmit an STD) when they understood that their maternal guardian disapproved of premarital sex (Dittus, Jaccard, \& Gordon, 1999). Thus parents' attitudes do affect the adolescent's sexual choices (Moore \& Rosenthal, 1991; O'Sullivan, Meyer-Bahlburg, \& Watkins, 2001).

In terms of racial differences and their impact on a teenager's sexual frequency and age of first sexual debut, non-Hispanic males are more likely to use condoms and initiate sexual activity later in life than are Hispanic-American males (Upchurch et al., 2001). Furthermore, Hispanic-American females are more likely to become pregnant earlier in life than any other American female (Solorio et al., 2004). Disparities in the amount of correct sexual knowledge parents held were also found for this ethnic minority (Gallegos, Villarruel, \& Gomez, 2007). Clearly there is a compounded effect between minorities living in less advantaged neighborhoods, as the majority of Caucasian-Americans live in middle class households. Often individuals have a mixture of correlates, such as low academic achievement, low socioeconomic status, and poor job availability, which frequently may lead to pregnancy as the most dependable option (Coley \& Chase-Lansdale, 2000).

\section{Impact of Adolescents' Family Composition, Goal Setting, and Religious Beliefs on Sexual Health Behaviors}

Family composition has been explored for its relations with sexual development. Single parent homes were related to permissive adolescent sexual behavior (Browning, Leventhal, \& Brooks-Gunn, 2004). Similarly, living without both biological parents was found to be associated with an earlier onset of a teenager's sexual debut (Miller, 2002). Furthermore, other studies indeed support that adolescents raised in non-intact families were involved in more premarital sexual activity (Flewelling \& Bauman, 1990; Furstenberg \& Teitler, 1994; Kieman, 1992; Ellis et al., 2003). Thus, living in a single parent home or with a caretaker other than their biological parents could pose a significant risk in itself for the teenager to initiate premature sexual activity.

Adolescents' personal variables have also been explored. Of specific interest for this study was the adolescents' own clarity of long-term goals, a variable rarely addressed in former research. Research shows that adolescents with few aspirations for future goals are more likely to be drawn to deviant peer groups, which in return exposes them to high risk behaviors (DiBlasio \& Blenda, 1994; Bogaert et al., 2008). In contrast, adolescents who have high personal goals and a strong desire for academic achievement tend to avoid behaviors that will interfere with their future goals (De Gaston, Weed, \& Jensen, 1996; Bandura et al., 2003).

Other potential personal correlates of sexual activity include adolescents' own religious beliefs. For instance, Jones, Darroch, \& Singh (2005) have shown that when religion is a significant part of teenagers' lives they are more likely to hold conservative sexual attitudes. Also, the social integration and support available through interaction with members of a religious community may serve to solidify acceptable sexual behaviors (Ellison \& Levin, 1998; McMillen et al., 2011). Religiosity may therefore be related to delayed sexual debut and 
more responsible sexual behaviors (Rostosky et al., 2004).

Clearly there are many variables that contribute to adolescent sexual development, and most of them have been studied in isolation or in small combinations. The purpose of this study was to simultaneously understand a variety of potential correlates of adolescents' age of first sexual intercourse and frequency of current sexual intercourse, while using a large, multiethnic sample including reports about both parents. A particular strength of this study is that it separately addressed the roles of mothers and fathers on the teenagers' sexual activity level. The specific research questions were: 1) Does age of first date correlate with age of first sexual intercourse? 2) Does age of first sexual intercourse vary by family composition (e.g., two-parent versus single-parent families)? 3) Do teenagers' clarity of long-term goals vary by their current frequency of sexual intercourse? 4) Are adolescents' sexual behaviors correlated with whether or not they know what each of their parents think about premarital sex and each parent's approval of premarital sex? 5) Can adolescents' abstinence/ sexual intercourse status, age of first sexual intercourse, and frequency of sexual behavior be predicted by a combination of key variables (clarity of long term goals, parents' values, sexual attitudes, age of first education about sexual intercourse)? 6) What role do religious beliefs play in adolescents' decisions to remain abstinent?

\section{Participants}

\section{Method}

Participants in this study came from a sample of 672 American adolescents (231 males, 413 females, 28 unreported) in the $9^{\text {th }}(n=178), 10^{\text {th }}(n=126)$, $11^{\text {th }}(n=192)$, and $12^{\text {th }}(n=151)$ grades $(n=25$ unreported). The mean age was 15.97 (SD=1.26). The ethnic breakdown was 204 African-American, 181 Caucasian, 183 Hispanic-American (primary Mexican-American), and 104 others. Most Caucasian students came from a primarily middle socioeconomic status (SES) suburban area high school, and most minority students were sampled from two urban primarily low SES area high schools of a large mid-western city. This was done in order to obtain diversity in the sample. For data analysis purposes, the urban low SES group was divided into two subgroups based upon which school they attended. One was a mixed-race public high school (primarily Hispanic and African-American) and the other was a primarily African-American public high school for pregnant and/or parenting females only. In all three subgroups (middle-SES, Caucasian, suburban; low-SES, mixed race, urban; and low-SES, African-American females, urban), the age range and dispersion were approximately even.

\section{Measures}

Questionnaires included a measure of sexual attitudes, sexual behaviors, family composition, and clarity of long-term goals, parental views, religious beliefs, dating patterns, and timing of education on sexual intercourse.

Sexual attitudes. Adolescents' sexual attitudes and goals were measured using three subscales from the Mathtech Attitude and Value Scales: Attitudes Toward Premarital Intercourse (Kirby, 1990). A five-item scale was used to assess adolescents' sexual attitudes (e.g., "Unmarried people should not have sex"). For all items, adolescents responded using the same five-point 
scale ( $1=$ Strongly Disagree, 5=Strongly Agree). In Kirby's (1990) samples, Cronbach's alpha coefficients were .94 for boys and .73 for girls. The current study yielded alphas of .88 and .62 , respectively.

Because the Pearson correlation coefficient shrinks artificially due to a small number of items, a correction procedure was used for the girls' personal sexual values alpha. The Spearman-Brown Prophecy formula demonstrates what the reliability of the instrument would be if additional similar quality items were added to the scale. In this case, the Spearman-Brown Prophecy Formula projected internal consistency, assuming the total number of items per subscale was 10 (a more typical number of items for subscales of this type) and yielded an alpha of .77 .

Sexual behaviors. Adolescents responded on a five-point scale to reveal how frequently they have engaged in sexual intercourse in the past year (ranging from "never" to "daily"). Higher scores represented greater frequency of sexual intercourse. Age of first sexual intercourse and sexual intercourse status (abstinent vs. not abstinent) were also assessed.

Adolescents' religious beliefs. If participants stated that they were not sexually active, they were asked to check one of eight reasons for their sexual inactivity. Religious beliefs were one of the eight possibilities. From this, a dichotomous "religious beliefs" variable was created, with adolescents either checking or not checking "religious beliefs" as a reason for avoiding sexual intercourse.

Age of first education about sexual intercourse. Teenagers were asked at what age/what grade that they were in when they were first taught about sexual intercourse.

Family composition. Family Composition was explored by asking the teenagers, "With whom do you live now?" Adolescents were told to mark all people that currently lived in their household (ranging from step-father to grandmother). Teens were categorized as living with a single parent, two parents, or one parent and another caregiver.

Clarity of long-term goals. Students were asked five questions on a five point scale, which focused on the teenagers' attitudes towards their sexuality and their long-term goals. The scale ranged from "strongly disagree" to "strongly agree."

Parental attitudes about premarital sex. Adolescents' perceptions of their parents' attitudes about premarital sex were assessed. Mothers and fathers (or similar parental figures) were assessed separately. The adolescents were asked whether or not they know their mothers'/fathers' view about premarital sex, and further on filled in detailed questions of about those views. Adolescents were told to answer about a parent or a parent-figure - it did not necessarily have to be a biological parent. The options for each of their father's and their mothers' views were presented on a 4-point scale. Options ranged from "she thinks that I should definitely NOT have sex before marriage" to "she thinks that it's okay if I have sex before marriage, but she wants me to use contraception." Prior studies (Kirby, 1990) have found Cronbach's alpha=.94. Alphas for the current sample were .89 (males) and .88 (females).

Dating patterns. Adolescents were asked, "How old were you when 
you went out on your first date?" Adolescents also filled in their age at first date.

\section{Procedure}

In addition to obtaining parental consent via a parental permission slip, participating adolescents signed an assent form to validate their voluntary participation. In each school, several classrooms were invited to participate. Approximately $67 \%$ of students approached at the mixed race urban school participated, and more than $95 \%$ of students approached at each of the two other schools participated This was most likely due to greater encouragement and support from teachers and their principals, as was observed by the researchers. Rates of behavior for the samples were similar to national averages. The sample is believed to be representative of the larger adolescent population, and it can be assumed that students who participated were not significantly different than those who did not participate. Surveys were completed during a single class period while supervised by the researcher and/or the teachers in the classrooms. Students were each given a packet containing all of the measures described in the above measures section at the same time. All procedures were approved by the University Institutional Review Board.

\section{Results}

Research questions 1 through 6 are addressed in separate sections below. Research question 7 has been integrated within research questions 1-6 as appropriate. For space purposes, only significant results are reported. Question 1: Does age of first date correlate with age of first sexual intercourse?

Among those who were non-virgins $(n=269)$, there was a low to moderate correlation between age of first date and age of first sexual intercourse overall $(r=0.346, p<0.01)$, as well as for boys from the urban school $(r=0.353$, $\mathrm{p}<0.01)$, and girls from the pregnant/parenting school $(r(77)=0.492, \mathrm{p}<0.01)$. Question 2: Does age of first sexual intercourse vary by family composition (i.e., two-parent versus single-parent families)?

An analysis of family composition revealed that $34.3 \%$ of the adolescents live in a household with only one parent, $23.1 \%$ live in a household with both parents, and $16.4 \%$ live with a parent and some other caretaker figure in the household. A significant amount $(26 \%)$ of adolescents did not respond to the questions about family composition. An Analysis of Variance (ANOVA) revealed that adolescents' age of first sexual intercourse did not significantly vary by family composition $(F(2,209)=0.806, p<0.05)$.

Question 3: Do teenagers' clarity of long-term goals vary by their current frequency of sexual intercourse?

The respondents' clarity of long term goals, although statistically significantly correlated, were weakly associated with frequency of sexual intercourse $(r(272)=.118, p<0.01)$. Further examination by genders and groups revealed no statistically significant relations.

Question 4: Are adolescents' sexual behaviors correlated with whether or not they know what each of their parents think about premarital sex and each parent's approval of premarital sex?

Results revealed that more liberal maternal attitudes were significantly correlated with adolescents' frequency of sexual intercourse, although the relation was weak $(r(182)=0.220, \underline{p}<0.01)$. However, maternal and paternal values 
about premarital sex were moderately strongly correlated, suggesting some degree of agreement in their view on teenage premarital sex $(r(119)=0.547$, $\mathrm{p}<0.01)$. Next, results are presented for various demographic subgroups. Among females from the urban school, greater knowledge of their fathers' views about premarital sex was correlated with their fathers having more liberal attitudes toward premarital sex $(r(13)=-0.705, p<0.01)$. Similarly, for these female adolescents, knowledge of their mothers' views about premarital sex values was inversely correlated with mothers' attitudes toward premarital sex ( $r$ $(26)=-0.512$, $\mathrm{p}<0.01$ ). Males from the suburban school indicated that their mothers' and fathers' views were fairly consistent with each other $(r(38)=0.604$, $\mathrm{p}<0.01)$ and that when their mothers held more liberal views, male adolescents were engaging in more frequent sexual behaviors $(r(46)=0.334, p<0.01)$. For females from the urban school, a strong correlation between their parents' attitudes toward premarital $\operatorname{sex}(r(11)=0.891, p<0.01)$ and frequency of sexual behaviors was reported.

Question 5: Can adolescents' abstinence/sexual intercourse status, age of first sexual intercourse, and frequency of sexual behavior be predicted by a combination of key variables (clarity of long term goals, parents' values, sexual attitudes, age of first education about sexual intercourse)?

Adolescent abstinence/sexual intercourse status was significantly predicted by the combination of clarity of long term goals, personal attitudes towards premarital intercourse, parental values, and age at time of first sexual education $\left(R^{2}=0.13, F(8,128)=2.42, p<0.05\right)$. Because the sample size was reduced significantly when only including those who have had sexual intercourse, further gender and race breakdowns were not conducted. Question 6: What role do religious beliefs play in adolescents' decisions to remain abstinent?

Using Chi-Square analysis, results revealed no significant interaction between religious beliefs and adolescents' decisions to remain abstinent $\left(x^{2}\right.$ $(33)=0.330, \underline{p}<0.566)$. These results were similar for each gender groups and each of the schools.

\section{Discussion}

The purposes of this study were to examine a variety of potential predictors of adolescents' age of sexual debut and frequency of sexual behavior. Gender and racial variations were also explored. Adolescents' sexual attitudes, sexual behaviors, religious beliefs, age of first education about sexuality, family composition, long-term goals, parental attitudes, and age of first date were all examined. It was hypothesized that more permissive sexual behavior and earlier onset of sexual intercourse in adolescents would be correlated with parental approval of premarital sex, weak religious values, single parent homes, less clarity of long-term goals, and earlier dating. Several themes were found in the results. Each is discussed below.

Interestingly, adolescents' religious beliefs were not related to their choice to remain abstinent or not. Also, family composition was not significantly related to adolescents' sexual behaviors. Hence, adolescents' sexual practices were similar regardless of whether they were living in a single parent home or in a household including two parental figures. Other parental variables were, 
however, related to adolescent sexual activity outcomes. First, parental values about premarital sex were somewhat correlated with adolescents' sexual behaviors, and, most consistently, maternal attitudes were related to adolescents' sexual choices. Permissive parental attitudes appeared to be related to a higher frequency of adolescent sexual behaviors. However, this is correlational data, and causal or directional inferences should not be made. Prior research suggests that parents often do not engage in sexual communication with their children until after sexual activity in their teens has already begun (Somers \& Paulson, 2000). Thus, the most likely explanation for these results here is that those parents with more liberal attitudes are more pressured to talk about what their adolescents are expressing interest in, and through that, they express values that may include messages that do not necessarily disapprove of premarital sex.

The results also demonstrated that a combination of less clarity about long term goals, more liberal parental attitudes, and earlier age of sexual education were related to higher frequency of sexual activity, lower age of first sexual intercourse, and less contraceptive use.

Adolescents' earlier age of first date was found to be related to an earlier age of onset of sexual intercourse. Although the relation was weak, it nonetheless may indicate that better sex education and heightened parental monitoring is likely to intervene in early dating leading to behaviors that set the stage for early sexual activity. This is especially important considering that early sexual debut has been linked to a variety of social, intrapersonal, and academic problems (Steinberg, 2005). Early sexual activity is also related to higher risks of STD transmission, lowered contraceptive use (Bersamin et al., 2008; Coker et al., 2000), and risk of dating violence (Coker et al., 2000). Thus, younger teens are more likely to expose themselves to higher risks and make less responsible decisions than would older adolescents.

There are limitations to this study that include the small sample sizes. Thus, some of these results should be addressed further in studies with larger and even more diverse samples. Also, variables such as individual cognitive factors were not measured. For example, prior research has indicated that individual cognitive variables (e.g., risk judgments and invulnerability) were related to sexual and other risk taking behavior and may have an impact on adolescents' decision making processes (Somers, Greenwald, \& Hillman, 2008; Halpern-Felsher et al., 2001). Additionally, the role of media was not addressed.

Clearly there are many variables that likely contribute to the development of healthy sexual behaviors. The specific goal of this study was to identify multiple variables from a demographically diverse sample and their relative contributions as identified in prior literature. Interesting patterns were observed that can be used to inform future research and current interventions with children and adolescents. Most specifically, when school counselors are generating either individual or school-wide prevention efforts, it is important to understand which factors are most linked to sexual risk taking behavior in adolescents. They can tailor their education to adolescents in individual meetings and/or group talks, as well as to parents both on an individual level (e.g., if their child is having particular difficulties) or preventively through an in-service to parents (e.g., a presentation at a PTA meeting). School counselors can inform teachers 
of information that will be useful to them in their interactions with students. Similarly, community counselors can utilize this information in didactic ways with their clients in order to help them to understand important key factors that should be addressed in an effort to improve children's potential outcomes. For instance, parents should be made aware that they could be talking to their children about sex before they start dating, as age of first intercourse coincides very closely with age of first date. This could maximize effectiveness of such communication. Additionally, as this research and other studies show, parents who communicate with their child about sex, but hold disapproving values about premarital sex, tend to rear adolescents that delay their sexual debut (Dittus, Jaccard, \& Gordon, 1998). Several research articles pointed at the importance of starting sex education during pre-adolescence (Wyckoff et al., 2008) and helping parents to be educated themselves about the information transmitted to their children (Gallegos, Villarruel, \& Gomez, 2007). Thus, parents could be taught how to educate their child about sex without seeming to encourage sexual activities and start such communication before their child's first date. Finally, family composition (single versus two-parent families) did not prove to be related to risky sexual behavior in this study. This supports the notion that universal sex education and early prevention programs are applicable to all families.

Overall, most of these research findings point to the interactional nature of risk factors instead of one single predictor for risky sexual behavior, such as a combination of living in a single parent and home, holding low SES, and holding racial or ethnic minority status (Upchurch et al., 2001). This calls for a multidimensional approach to assessment and intervention efforts by counselors, as no one factor, but rather interactional processes (e.g., kind of sex education received by parents, values parents hold about premarital sex, and goals and aspirations adolescents hold, etc.), shape the landscape of adolescent sexual risk behavior.

\section{References}

Ballard, S. M., \& Morris, M. L. (1998). Sources of sexuality information for university students. Journal of Sex Education and Therapy, 23, 278-287.

Bandura, A., Caprara, G.V., Barbaranelli, C., Gerbino, M., \& Pastorelli, C. (2003). Role of affective self-regulatory efficacy in diverse spheres of psychosocial functioning. Child Development, 74(3), 769-782.

Bersamin, M., Todd, M., Fisher, D., Hill, D.L., Grube, J.W., \& Walker, S. (2008). Parenting practices and adolescent sexual behavior: A longitudinal study. Marriage and Family, 70(1), 97-112.

Bogaert, A.F., Busseri, M.A., Chalmers H., \& Willoughby T. (2008). On the association between sexual attraction and adolescent risk behavior involvement: Examining mediation and moderation. Developmental Psychology, 44(1) 69. 
Browning, C.R., Leventhal, T., \& Brooks-Gunn, J. (2004). Neighborhood context and racial differences in early adolescent sexual activity. Demography, 41(4), 697-720.

Centers for Disease Control and Prevention. (2006). "Youth risk behavior surveillance-United States, 2005". Morbidity and Mortality Weekly Report, Surveillance Summaries, 55(No. SS-5).

Centers for Disease Control and Prevention. (2009). HIV Surveillance Report: Diagnosis of HIV Infection and AIDS in the United States and Dependent Areas, 21 (1).

Coley, R.L., \& Chase-Lansdale, P.L. (2000). Welfare receipt, financial strain, and African-American adolescent functioning. Social Service Review, 74(3), 380-404.

Coley, R.L., Drzal, E.V., \& Schindler, H.S. (2009). Fathers' and mothers' parenting predicting and responding to adolescent sexual risk behaviors. Child Development, 80(3), 808-827.

Coker, A.L., McKeown, R.E., Sanderson, M., Davis, K.E., Valois, R.F., \& Huebner, E.S. (2000). Severe dating violence and quality of life among South Carolina high school students. American Journal of Preventive Medicine, 19, 220-227.

De Gaston, J. F., Weed, S., \& Jensen, L. (1996). Understanding gender differences in adolescent sexuality. Adolescence, 31, 217-231.

DiBlasio, F. \& Blenda, B. (1994). A conceptual model of sexually active peer association. Youth \& Society, 25(3), 351-367.

Dittus, P.J., Jaccard, J., \& Gordon, V.V. (1999). Direct and non-direct communication of maternal beliefs to adolescents: Adolescent motivation for premarital sexual activity. Journal of Applied Social Psychology, 29, 19271963.

Dilorio, C., Kelley, M., \& Hockenberry-Eaton, M. (1999). Communication about sexual issues: Mothers, fathers, and friends. Journal of Adolescent Health, 24, 181-189.

Ellis, B. J., Bates, J.E., Dodge, K.A., Fergusson, D.M., Horwood, L.J., Pettit, G.S., et al. (2003). Does father absence place daughters at special risk for early sexual activity and teenage pregnancy? Child Development, 74(3), 801-821.

Ellison, C.G., \& Levin, J.S. (1998). The religion-health connection: Evidence, theory, and future directions. Health Education and Behavior, 25, 700720. 
Fiese, B.H., Tomcho, T.J., Douglas, M., Josephs, K., Poltrock, S., \& Baker, T. (2002). A review of 50 years of research on naturally occurring family routines and rituals: Cause for celebration? Journal of Family Psychology, 16, 381-390.

Flewelling, R.L., \& Bauman, K.E. (1990). Family structure as a predictor of initial substance use and sexual intercourse in early adolescence. Journal of Marriage and the Family, 52, 171-180.

Furstenberg, F.F., Jr., \& Teitler, J.O. (1994). Reconsidering the effects of marital disruption: What happens to children of divorce in early adulthood? Journal of Family Issues, 15, 173-190.

Gallegos, E.C., Villarruel, A.M., \& Gomez, M.V. (2007). Research brief: Sexual communication and knowledge among Mexican parents and their adolescent children. JANAC-Journal of the association of nurses in AIDS care, 18(2), 28-34.

Halpern-Felsher, B.L., Millstein, S.G., Ellen, J., Adler, N., Tschann, J., \& Biehl, M. (2001). The role of behavioral experience in judging risks. Health Psychology, 20, 120-126.

Jones, R.K., Darroch, J.E., \& Singh, S. (2005). Religious differentials in the sexual and reproductive behaviors of young women in the United States. Journal of Adolescent Health, 36(1).

Kieman, K.E. (1992). The impact of family disruption in childhood on transitions made in young adult life. Population Studies, 46, 213-234.

Kirby, D. (1990). Sexuality Questions and Scales for Adolescents. Santa Cruz, CA: ETS.

Lefkowitz, E.S., Sigman, M., \& Au, T.K. (2000). Helping mothers discuss sexuality and AIDS with adolescents. Child Development, 71(5), 1383-1394.

McMillen, E.K., Herbert, H., McBride W., Jr., \& Duane, C. (2011). Religious orientation and sexual attitudes and behaviors. Journal of Research on Christian Education, 20(2), 195-206.

Miller, B. C. (2002). Family influences on adolescent sexual and contraceptive behavior. The Journal of Sex Research, 39(1), 22-26.

Moore, S., \& Rosenthal, D. (1991). Adolescent invulnerability and perceptions of AIDS risk. Journal of Adolescent Research, 6, 164-180. 
Moore, M.R., \& Chase-Lansdale, L.P. (2001). Sexual intercourse and pregnancy among African-American girls in high-poverty neighborhoods: The role of family and perceived community environment. Journal of Marriage and the Family, 63(4), 1146-1157.

Muller, C., Frisco, M.L., \& Pearson, J. (2006). Parental involvement, family structure, and adolescent sexual decision making. Sociological Perspectives, 49 (1), 67-90.

O'Sullivan, L.F., Meyer-Bahlburg, H.F.L., \& Watkins, B.X. (2001). Motherdaughter communication about sex among urban African American and Latino families. Journal of Adolescent Research, 16, 269-92.

Ohalete, N. (2007). Adolescent sexual debut: A case for studying African American father-adolescent reproductive health communication. Journal of Black Studies, 37(5), 737-752.

Perper, K., Peterson, K., \& Manlove, J. (2010). Diploma attainment among teen mothers. Child Trends, Fact Sheet Publication \#2010-01: Washington, D.C.

Ream, G.L., \& Savin-Williams, R.C. (2005). Reciprocal associations between adolescent sexual activity and quality of youth-parent interactions. Journal of Family Psychology, 19, 171-179.

Regnerus, M. D. (2005). Talking about sex: Religion and patterns of parentchild communication about sex and contraception. The Sociological Quarterly,46(1), 79-105.

Rostosky, S.S., Wilcox, B.L., Wright, M.L.C., \& Randall, B.A. (2004). The impact of religiosity on adolescent sexual behavior: A review of the evidence. Journal of Adolescent Research, 19(6), 677-697.

Saewyc, E.M., Pettingell, S., \& Magee, L.L. (2003). The prevalence of sexual abuse among adolescents in school. Journal of School Nursing, 19 (5), 266-272.

Somers, C.L., \& Fahlman, M.M. (2001). The effectiveness of the "baby think it over" teen pregnancy prevention program. Journal of School Health, 71(5), 188-195.

Somers, C.L., \& Gleason, J.H. (2001). Does the source of sex education predict adolescents' sexual knowledge, attitudes, and behaviors? Education, 121(4), 674-681. 
Somers, C.L., Greenwald, H.D., \& Hillman, S. (2008). Consequence consideration, invulnerability, and peer behaviors: Predicting adolescent risk behaviors. Poster presented at the National Association of School Psychologists (NASP) Annual Convention, New Orleans, LA.

Somers, C.L., \& Paulson, S.E. (2000). Students' perceptions of parentsadolescent closeness and communication about sexuality: Relations with sexual knowledge, attitudes, and behaviors. Journal of Adolescence, 23, 629-644.

Somers, C.L., \& Vollmar, W. (2006). Parent-adolescent relationships and adolescent sexuality: Closeness, communication, and comfort among diverse U.S. adolescent samples. Social Behavior and Personality, 34 (4), 451-460.

Solorio, M.R., Hongjian, Y.E., Brown, R.E., Becerra, L., \& Gelberg, L. (2004). A comparison of Hispanic and White adolescent females' use of family planning services in California. Perspectives on Sexual and Reproductive Health, 36(4), 157-161.

Steinberg, L. (2005). Adolescence ( $7^{\text {th }}$ ed.). New York: McGraw-Hill.

Upchurch, D.M., Aneshensel, C.S., Mudgal, J., \& McNeely, C.S. (2001). Sociocultural contexts of time to first sex among Hispanic adolescents. Journal of Marriage and Family, 63(4), 1158-1169.

Wyckoff, S.C., Miller, K.S., Forehand, R., Bau, J.J., Fasula, A., Long, N., \& Armistead, L. (2008). Patterns of sexuality communication between preadolescents and their mothers and fathers. Journal of Child and Family Studies, 17(5). 